\title{
Exercise training improves physical fitness in patients with pulmonary arterial hypertension: a systematic review and meta-analysis of controlled trials
}

\author{
Roselien Buys*, Andrea Avila and Véronique A Cornelissen
}

\begin{abstract}
Background: Pulmonary arterial hypertension $(\mathrm{PAH})$ is a progressive disorder characterized by hypertension in the pulmonary arteries. PAH leads to symptoms such as shortness of breath, dizziness, leg edema and chest pain, impacting heavily on quality of life. The aim of this systematic review and meta-analysis was to determine the effect of exercise training to improve physical fitness and functionality in patients with PAH.

Methods: A search was conducted for controlled trials using the databases Medline, Embase, SPORT Discus and Cochrane Central Register of Controlled Trials. Studies were included if at least $80 \%$ of the participants presented with group $1 \mathrm{PAH}$ and if the intervention consisted of an exercise training program of at least 3 weeks duration. Data were extracted on study quality, participant and exercise intervention characteristics, and outcomes. Data were pooled by the generic inverse variance method using random effect models and were expressed as weighted means and 95\% confidence intervals (Cl).

Results: Of 110 identified abstracts, 5 studies with 106 patients (exercise: 53; control: 53; mean age 49.7 years) were included. Disease severity ranged from mild to severe; 96 patients suffered from PAH, 10 patients had chronic thromboembolic pulmonary hypertension. Exercise training led to an increase in 6 minute walk distance $(72.5 \mathrm{~m}$; $95 \% \mathrm{Cl} 46.0 \mathrm{~m}$ to $99.1 \mathrm{~m} ; \mathrm{p}<0.0001)$ and peak oxygen uptake $(2.16 \mathrm{~mL} / \mathrm{kg} / \mathrm{min} ; 95 \% \mathrm{Cl} 2.16$ to $3.93 ; \mathrm{p}=0.02)$. No severe adverse events during exercise were reported.
\end{abstract}

Conclusions: Our findings suggest that an exercise training program positively influences exercise tolerance and functional capacity in patients with PAH.

Keywords: Pulmonary arterial hypertension, Exercise training, Exercise capacity

\section{Background}

Pulmonary arterial hypertension (PAH) is characterized by changes in mostly the distal pulmonary arteries. This causes an increase in pulmonary vascular resistance, which in turn restricts the blood flow through the pulmonary circulation $[1,2]$. In order to maintain the blood flow, the pulmonary artery pressure increase which leads to right ventricular overload, hypertrophy and dilatation [1]. The physiologic response of the pulmonary vasculature to exercise is different from normal in individuals

\footnotetext{
* Correspondence: roselien.buys@faber.kuleuven.be

Department of Rehabilitation Sciences, Tervuursevest 101, B 1501, B-3001, Leuven, Belgium
}

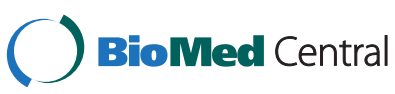

(c) 2015 Buys et al.; licensee BioMed Central. This is an Open Access article distributed under the terms of the Creative Commons Attribution License (http://creativecommons.org/licenses/by/4.0), which permits unrestricted use, distribution, and reproduction in any medium, provided the original work is properly credited. The Creative Commons Public Domain Dedication waiver (http://creativecommons.org/publicdomain/zero/1.0/) applies to the data made available in this article unless otherwise stated. with PAH and they generally show a reduced exercise capacity [3]. Advances in the understanding and management of pulmonary arterial hypertension have enabled earlier diagnosis and improved prognosis. However, despite best available therapy, symptoms of exertional dyspnea and fatigue are commonly reported and result in a reduced capacity to perform daily activities and impaired quality of life.

Exercise training has demonstrated efficacy in individuals with other respiratory and cardiovascular diseases [4-7]. Historically, however, exercise training has not been utilized as a form of therapy in PAH due to the perceived risk of sudden cardiac death and the theoretical possibility

rens otherwise stated. 
that exercise would lead to a worsening of pulmonary vascular hemodynamics and deterioration in right heart function. Now, with the advances in pharmacological management, determining the safety and benefits of exercise training in this population has become more relevant. The Task Force for the Diagnosis and Treatment of Pulmonary Hypertension of the European Society of Cardiology and the European Respiratory Society therefore state that more data are required in order to be able to make recommendations regarding physical activity and supervised rehabilitation in patients with PAH [1]. Recently, some studies of supervised and home-based exercise training in PAH have been published and it seems worthwhile to summarize their results in order to provide some evidence for the clinicians to rely on.

Therefore, the aim of this systematic review was to apply the meta-analytic approach in controlled trials in order to determine the effects of exercise training on functional status and exercise capacity.

\section{Methods}

Literature search

A systematic literature search was conducted in the electronic Pubmed database from its inception to December 2013 using following terms: (medical subject heading (MeSH-term)) 'exercise' or (MeSH term) 'rehabilitation' or (field term) 'exercise training' AND (MeSH-term) 'pulmonary hypertension' or (field term) 'pulmonary arterial hypertension'; results were filtered by 'clinical trials' and limitations were 'English, French, Dutch or German language'.

From this search, we only included articles specifically addressing the effects of a supervised exercise training program in patients with pulmonary hypertension. In addition, the reference lists from published original and review articles were searched manually to identify other possible eligible studies. Embase, SPORTDiscus and The Cochrane Central Register of Controlled Trials were furthermore consulted with the same search terms.

Studies were included in the meta-analysis if they were: Controlled trials 1) including a comparative control group and an intervention group; 2) with an intervention program of at least 3 weeks duration; 3) in patients groups of which at least $80 \%$ is diagnosed with PAH as defined according to the updated clinical classification of pulmonary hypertension [1]; 4) reporting preand post-intervention mean and standard deviation (SD) (or standard error) of 6 minute walking distance in intervention and control groups or mean change and standard deviation (or standard error) in intervention and control groups; 5) published in a peer-reviewed journal up to December 2013. Exclusion criteria included any studies not meeting all criteria described above.

\section{Outcomes}

The primary outcome measure was change in 6 minute walking distance (6MWD). Secondary outcomes included changes in peak oxygen uptake (peak $\mathrm{VO}_{2}$ ), peak heart rate and World Health Organization Functional Class (WHO-FC).

\section{Data extraction}

A specific developed data extraction sheet was used to extract data on study source, study design, study quality, sample size, characteristics of the participants, exercise interventions, and the different outcomes in each study included in the meta-analysis. Data were extracted by the first two authors (RB and AA) independently from each other. The overall agreement rate prior to correcting discrepant items was 0.64. Disagreements were resolved by consensus.

\section{Study quality}

Study quality was assessed using an adapted PEDro-scale [8]. This 11-item questionnaire is designed to collect data on eligibility criteria, random allocation, concealed allocation, similarity of baseline values, blinding of therapists and/or assessors, key outcomes, intention-to-treat analysis, between group differences, and point and variability measures. The quality criteria 'blinding of participants' and 'blinding of therapists' were omitted, since they were not applicable in the included intervention studies. All questions were binary. The minimum score was 0 and the maximum was 8 , with a higher number reflecting a better study quality. The PEDro-scale has been reported to be valid and reliable $[9,10]$. Using Cohen's kappa statistic, overall inter-rater agreement was 0.73 . Disagreements were resolved by consensus. Trials were not excluded based on quality.

\section{Statistical analysis}

Excel 2010 and Review Manager Software (RevMan 5.1; Cochrane Collaboration, Oxford, UK) were used for statistical analyses. Descriptive data are reported as mean \pm standard deviation (SD) or median and range. The mean baseline values were calculated by combining mean values from the intervention and control groups, weighted by the number of participants in the final analysis in each study group.

Effect sizes for primary and secondary outcomes were calculated by subtracting the pre-intervention value from the post-intervention value for both study groups. The net treatment effect was then obtained by subtracting the change score difference in the control group from the change score difference of the intervention group. Review Manager Software calculated the variances from the inserted pooled SDs of change scores in the intervention and control groups. However, some studies 
reported only the SDs or standard errors of mean at baseline and post-intervention. Therefore, change scores SDs that were missing in these studies were calculated from pre and post SD values, using the following formula: SDchange $=\sqrt{ }\left[(\text { SDpre })^{2}+(\text { SDpost })^{2}-2 \times \operatorname{corr}(\right.$ pre, post $) \times$ SDpre $\times$ SDpost] [11], for which a correlation coefficient of 0.5 between the pre and post values was assumed. The primary and secondary outcomes were combined using random-effects models, a preferred approach that incorporates heterogeneity into the model $[12,13]$. Each effect size was weighted by the inverse of its variance. The results are reported as weighted means and 95\% confidence intervals (CI). Two sided tests for overall effects were considered significant at $\mathrm{p} \leq 0.05$.

Statistical heterogeneity among the trials was assessed using Cochrane's Q statistic and an alpha value for statistical significance of 0.10 indicated significant heterogeneity. In addition, we report $\mathrm{I}^{2}$ statistics, which assesses consistency of treatment effects across trials. $\mathrm{I}^{2}$ between $25 \%$ and $50 \%$ represents small amounts of inconsistency, whereas between $50-75 \%$ and $>75 \%$ represents medium to large amounts of heterogeneity [14]. To examine the influence of each study on the overall results, sensitivity analyses were also performed with each study deleted from the model once. Finally, funnel plots were used to assess the potential of small publication bias. Funnel plot asymmetry was evaluated by use of Begg and Egger tests, and a significant publication bias was considered if the $\mathrm{p}$ value was $<0.10$. The trim and fill computation was used to estimate the effect of publication biases on the interpretation of the results.

\section{Results}

\section{Literature search}

A PRISMA flow diagram of the literature search and selection is presented in Figure 1. From 110 potentially relevant studies retrieved from the search, only 6 trials met our inclusion criteria. However, two studies $[15,16]$ used the same population and intervention, of which we included the most complete publication in terms of primary and secondary outcomes [15].

\section{Characteristics of the participants and study designs}

A summary of the included studies is provided in Table 1. Four of the five studies were randomized clinical trials, the other one was a non-randomized clinical trial. Four studies used a parallel design; the remaining one used a cross-over design. All studies were published between 2006 and 2013. The exercise intervention and control groups consisted each of 53 participants. The results of the adapted PEDro-scale, used to evaluate study quality, are presented in Table 2. The median PEDro score was 6, with a range from 3 [17] to 8 [18].
In total, 5 patients dropped out from the studies, resulting in a total of 101 participants (28 men) that could be included in the final analysis: 50 of them completed an exercise intervention and 51 were control subjects. Four studies included a 'usual care' control group (17-20) and in one study, control group participants received an educational program [15].

Baseline characteristics of the study participants are summarized in Table 3. All trials included both men and women, except for Chan who, by chance, included only women [15].

\section{Intervention characteristics}

Table 1 also provides a description of the intervention characteristics of each trial. Study duration ranged between 3 and 15 weeks (median 12). The frequency of exercise training varied between 2 and 5 sessions weekly (median 3), with an average duration of 46 min per session (range 30-60). The average intensity was between 60 and $80 \%$ of peak heart rate in four studies [17-20], and $70-80 \%$ of heart rate reserve in the remaining study [15]. Mode of exercise was aerobic interval training along with resistance exercises in 3 trials $[17,18,20]$, supplemented with respiratory training in two of them: Fox et al. adopted a training program with continuous aerobic exercises and resistance exercise [19] whereas Chan et al. used intensive treadmill exercise training [15].

\section{Assessment of primary and secondary outcomes}

In all included studies, the 6-minute walk test was performed in accordance with appropriate guidelines [21]. Peak $\mathrm{VO}_{2}$ and peak heart rate were measured in three studies using a graded maximal exercise test on an upright cycle ergometer [19], on a treadmill [15] or on a supine cycle ergometer [18]. Four out of the five studies reported the WHO-FC before and after the intervention. Mean effect sizes and Z-scores are summarized in Table 4.

\section{Changes in 6MWD}

As shown in Figure 2, 6MWD increased significantly following exercise with a mean increase of $72.2 \mathrm{~m}(95 \% \mathrm{CI}$ 45.7 to $98.6 ; \mathrm{p}<0.001)$; heterogeneity and inconsistency were small $\left(\mathrm{Q}=5.72, \mathrm{p}=0.22 ; \mathrm{I}^{2}=30 \%\right)$. When each trial was deleted from the model once, the results remained statistically significant.

\section{Secondary outcomes}

Figure 3 shows the mean changes in peak $\mathrm{VO}_{2}$ with training. Peak $\mathrm{VO}_{2}$ increased significantly by exercise training $(\mathrm{p}=0.02)$. However, when the largest study [18] was deleted from the model, statistical significance could not be met anymore. 


\section{PRISMA 2009 Flow Diagram}

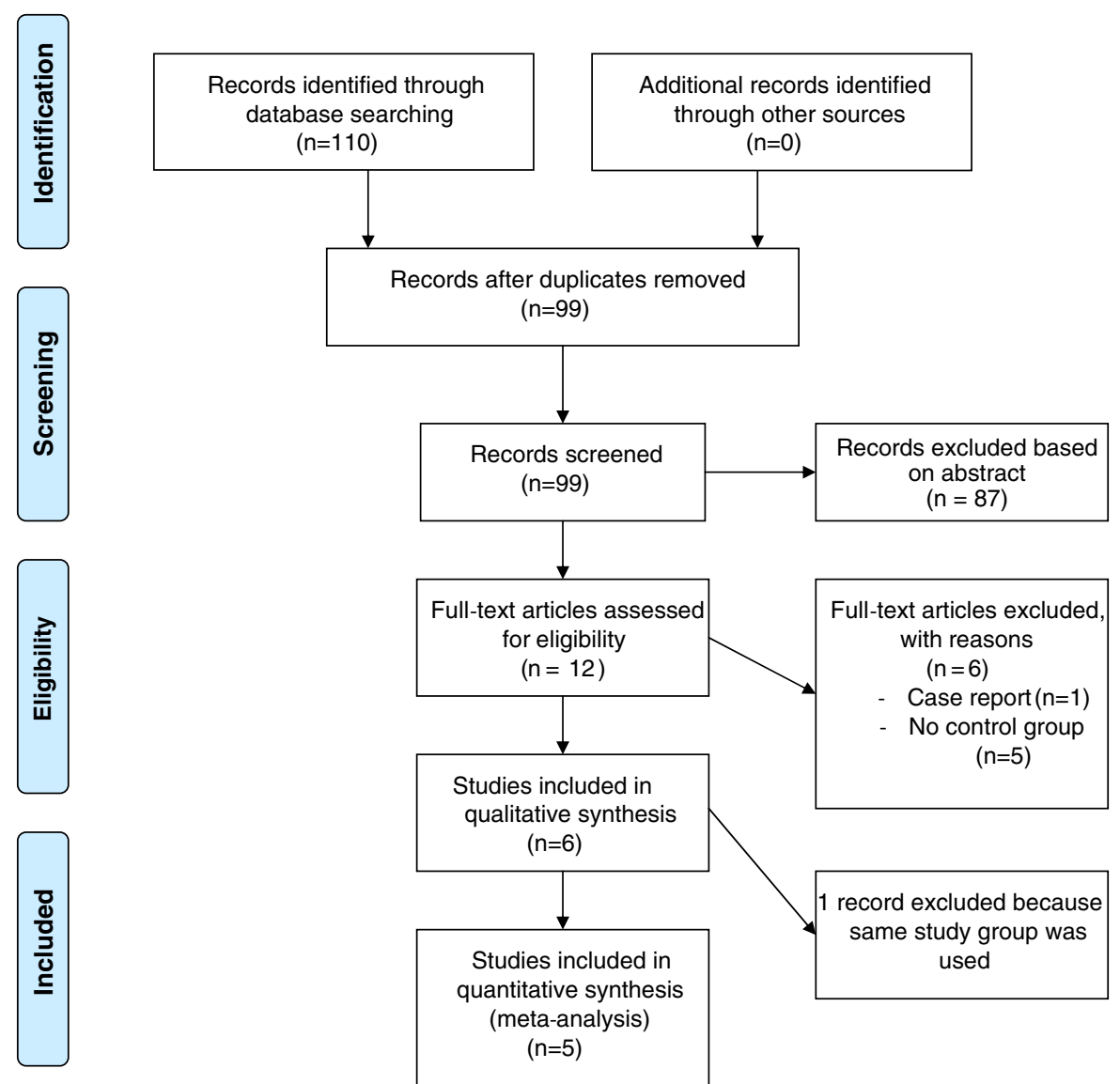

Figure 1 PRISMA flow chart of the literature search. From: Moher D, Liberati A, Tetzlaff J, Altman DG, The PRISMA Group (2009). Preferred Reporting Items for Systematic Reviews and Meta-Analyses: The PRISMA Statement. PLoS Med 6(6): e1000097. doi:10.1371/journal.pmed1000097 For more information, visit www.prisma-statement.org.

A simultaneous change in peak heart rate due to training could not be documented $(\mathrm{p}=0.54)$.

Two out of the four studies who reported WHO-FC, documented a functional improvement as assessed by this instrument, but overall no significant reduction of WHO-FC was induced by exercise training $(\mathrm{p}=0.12)$.

\section{Publication bias}

According to the tests of Begg and Egger, funnel plots of 6MWD and peak $\mathrm{VO}_{2}$ did not show any signs of significant publication bias ( $p>0.5$ for all). Duval and Tweedie's trim and fill method indicated that one (for $6 \mathrm{MWD}$ ) or two (peak $\mathrm{VO}_{2}$ ) studies could be missing at the right side of the mean effect size. Adjustment of the data for these missing data did not change the results. (see Additional files 1 and 2).

\section{Discussion}

This systematic review and meta-analysis is the first to focus on the effect of exercise training on physical fitness and functional capacity in patients with PAH. The analysis, in which 5 studies could be included, showed that exercise training can result in clinically relevant improvements of physical and functional capacity.

The idea that exercise training programs may potentially be beneficial for patients with $\mathrm{PAH}$ became only recently accepted [1]. Exercise based rehabilitation for patients with PAH is now considered as a new adjunct treatment option in order to improve their functional capacity and quality of life. Following here, some proof of concept studies have been performed; most of them showing significant beneficial effects of exercise training on functional capacity and/or exercise capacity, but not 
Table 1 Description of the patient populations and characteristics of the exercise training programs

\begin{tabular}{|c|c|c|c|c|c|c|c|c|c|c|}
\hline Author & Year & Origin & Design & Patient population & NYHA & $\begin{array}{l}\text { Age } \\
\text { (year) }\end{array}$ & Number at baseline & Exercise intervention & Control & $\begin{array}{l}\text { Assessment } \\
\text { of physical } \\
\text { fitness }\end{array}$ \\
\hline Mereles et al. & 2006 & Germany & Cross-over & $\begin{array}{l}\text { PAH }(80 \%) \text { or } \\
\text { chronic pulmonary } \\
\text { thromboembolic } \\
\text { disease }(20 \%)\end{array}$ & $\|-I V$ & 50 & $\begin{array}{l}\text { Intervention: } 15 \\
\text { (10 female/5 male); } \\
\text { Control: } 15 \\
\text { (10 female/5 male) }\end{array}$ & $\begin{array}{l}3 \text { weeks in-hospital }+12 \text { weeks home-based } \\
\text { aerobic interval training along with resistance } \\
\text { and respiratory exercises, } 5 \text { sessions/week, } \\
30-60 \text { min/session, } 60-80 \% \text { of peak HR }\end{array}$ & Usual care & 6MWT, CPET \\
\hline Martinez-Quintana et al. & 2010 & Spain & Parallel & $\begin{array}{l}\text { PAH associated } \\
\text { with congenital } \\
\text { heart disease }\end{array}$ & $\|-I V$ & 27.7 & $\begin{array}{l}\text { Intervention: } 4 \\
\text { (2 female/2 male); } \\
\text { Control: } 4 \\
\text { (3 female, } 1 \text { male) }\end{array}$ & $\begin{array}{l}3 \text { months supervised aerobic interval training } \\
\text { and resistance exercise, } 2 \text { sessions/week, } \\
30-60 \mathrm{~min} / \text { session, } 60-80 \% \text { of peak HR }\end{array}$ & Usual care & $6 \mathrm{MWT}$ \\
\hline Fox et al. & 2011 & Israel & Parallel & $\begin{array}{l}\text { PAH }(91 \%) \text { or chronic } \\
\text { thromboembolic } \\
\text { PH (9\%) }\end{array}$ & $\|-\|$ & 51.5 & $\begin{array}{l}\text { Intervention: } 11 \\
\text { (10 female/1 male); } \\
\text { Control: } 11 \\
\text { (5 female, } 6 \text { male) }\end{array}$ & $\begin{array}{l}3 \text { months supervised continuous aerobic } \\
\text { and resistance exercise, } 2 \text { sessions/week, } \\
60 \text { min/session, } 60-80 \% \text { of peak HR }\end{array}$ & Usual care & 6MWT, CPET \\
\hline Ley et al. & 2013 & Germany & Parallel & $\begin{array}{l}\text { PAH }(80 \%) \text { or } \\
\text { chronic inoperable } \\
\text { tromboembolic } \\
\text { PH (20\%) }\end{array}$ & $\|-\| \mid$ & 50.5 & $\begin{array}{l}\text { Intervention: } 10 \\
\text { (8 female/2 male); } \\
\text { Control: } 10 \\
\text { (6 female, } 4 \text { male) }\end{array}$ & $\begin{array}{l}3 \text { weeks supervised aerobic interval training } \\
\text { along with resistance and respiratory } \\
\text { exercises, } 5 \text { sessions/week, 30-60 min/ } \\
\text { session, } 60-80 \% \text { of peak HR }\end{array}$ & Usual care & $6 \mathrm{MWT}$ \\
\hline Chan et al. & 2013 & USA & Parallel & $\mathrm{PAH}$ & I - IV & 54.4 & $\begin{array}{l}\text { Intervention: } 13 \\
\text { (13 female/0 male); } \\
\text { Control: } 13 \\
\text { (13 female, } 0 \text { male) }\end{array}$ & $\begin{array}{l}10 \text { weeks supervised treadmill walking, } \\
3 \text { sessions/week, } 30-45 \mathrm{~min} / \mathrm{session}, \\
70-80 \% \text { of heart rate reserve + patient } \\
\text { education }\end{array}$ & $\begin{array}{l}\text { Patient } \\
\text { education } \\
\text { only }\end{array}$ & 6MWT, CPET \\
\hline
\end{tabular}


Table 2 PEDro-scores for the intervention trials included in the meta-analysis

\begin{tabular}{|c|c|c|c|c|c|c|c|c|c|c|}
\hline Study (year) & $\begin{array}{l}\text { Eligibility } \\
\text { criteria }\end{array}$ & $\begin{array}{l}\text { Randomly } \\
\text { allocated }\end{array}$ & $\begin{array}{l}\text { Allocation } \\
\text { concealed }\end{array}$ & $\begin{array}{l}\text { Baseline } \\
\text { similar }\end{array}$ & $\begin{array}{l}\text { Blinding } \\
\text { assessors }\end{array}$ & $\begin{array}{l}\text { Key } \\
\text { outcome } \\
85 \%\end{array}$ & $\begin{array}{l}\text { Intention } \\
\text { to treat }\end{array}$ & $\begin{array}{l}\text { Between } \\
\text { group }\end{array}$ & $\begin{array}{l}\text { Point and } \\
\text { variability } \\
\text { measure }\end{array}$ & $\begin{array}{l}\text { Total PEDro } \\
\text { score }\end{array}$ \\
\hline Mereles (2006) & 1 & 1 & 1 & 1 & 1 & 1 & 1 & 1 & 1 & 8 \\
\hline Martinez-Quintana (2010) & 1 & 0 & 0 & 0 & 0 & 1 & 0 & 0 & 1 & 2 \\
\hline Fox (2011) & 1 & 0 & 1 & 0 & 1 & 1 & 1 & 1 & 1 & 6 \\
\hline Ley (2013) & 1 & 1 & 0 & 1 & 0 & 1 & 0 & 1 & 1 & 5 \\
\hline Chan (2013) & 1 & 1 & 1 & 1 & 1 & 0 & 1 & 1 & 1 & 7 \\
\hline
\end{tabular}

all (Chan [15], Martinez [17], Fox [19] for peak $\mathrm{VO}_{2}$ ). Hence, the existing evidence is inconclusive and insufficient to result in the implementation of exercise programs in routine clinical care for patients with PAH. By pooling data from published controlled trials, we aimed to increase the statistical power and resolve the uncertainty. We could show that exercise training is effective for improving both functional and exercise capacity.

In todays practice the 6MWD is most often used as an endpoint to assess the benefit of therapies in PAH. It is a measure of functional capacity. This meta-analysis

Table 3 Baseline characteristics of the study participants

\begin{tabular}{|c|c|c|}
\hline Variable & Exercise & Control \\
\hline Patients (n) & $\begin{array}{l}53 \\
(40 \mathrm{~F}, 10 \mathrm{M})\end{array}$ & $\begin{array}{l}53 \\
(35 \mathrm{~F}, 18 \mathrm{M})\end{array}$ \\
\hline Mean age (years) & 48.5 & 50.8 \\
\hline \multicolumn{3}{|l|}{ Pulmonary hypertension diagnosis (n) } \\
\hline $\mathrm{PAH}$ & 50 & 46 \\
\hline Ideopathic PAH & 12 & 14 \\
\hline Hereditary PAH & 0 & 1 \\
\hline $\begin{array}{l}\text { PAH associated with congenital } \\
\text { heart disease }\end{array}$ & 5 & 4 \\
\hline $\begin{array}{l}\text { PAH associated with connective } \\
\text { tissue disease }\end{array}$ & 14 & 14 \\
\hline PAH associated with portal hypertension & 1 & 1 \\
\hline Drug induced PAH & 0 & 1 \\
\hline PAH subtype not specified & 16 & 11 \\
\hline $\begin{array}{l}\text { Chronic thromboembolic pulmonary } \\
\text { hypertension }\end{array}$ & 3 & 7 \\
\hline \multicolumn{3}{|l|}{ WHO-FC (n) } \\
\hline Class I & 1 & 0 \\
\hline Class $\|$ & 12 & 13 \\
\hline Class III & 24 & 28 \\
\hline Class IV & 2 & 1 \\
\hline Not reported (Fox et al.) & 11 & 11 \\
\hline Mean pulmonary artery pressure $(\mathrm{mmHg})^{*}$ & 49 & 47.1 \\
\hline 6 minute walking test distance (m) & 401 & 408 \\
\hline
\end{tabular}

$n=$ number; $P A H$ : pulmonary arterial hypertension; $W H O-F C=$ World Health Organization Functional Class.

*Not reported in Martinez-Quintana et al, mean of 4 remaining studies. documented that an exercise training program of around 12 weeks can significantly improve the 6MWD with $72 \mathrm{~m}$ on average. This gain in walking distance is larger than that reported for patients with chronic obstructive pulmonary disease [22,23] or chronic heart failure [24]. Whereas it remains to be determined which minimum increase in 6MWD has to be reached in patients with PAH in order to obtain a clinically relevant improvement, a change of more than 50 meters has been proposed as representative of a clinically meaningful change in most disease states [25]. On the other hand, short-term improvements in 6MWD due to medical treatment could so far not be related to an improved longer-term prognosis [26] even though a baseline distance less than approximately $330 \mathrm{~m}$ on the 6MWD has been shown to be associated with increased mortality in PAH [27]. In line with these results, Golpe and colleagues in non-group $1 \mathrm{PAH}$ patients reported that a distance less than $400 \mathrm{~m}$ was predictive of a significantly worse prognosis [28]. In our study, mean baseline 6MWD was already more than 400 meter, however it is anticipated that the average observed gain in 6MWD of $72 \mathrm{~m}$ due to exercise training, will have shifted a part of the weaker patients towards a 6MWD larger than $400 \mathrm{~m}$ and thus towards a more favorable prognosis.

Overall, cardiopulmonary exercise testing is the preferred method for assessing changes associated with exercise training [29]. Despite being less often used, cardiopulmonary exercise testing should also be considered as the gold standard measurement of exercise capacity

Table 4 Effect sizes of primary and secondary outcomes of the meta-analysis

\begin{tabular}{lllll}
\hline Variable & $\begin{array}{l}\text { Study } \\
\text { groups }\end{array}$ & $\mathbf{n}$ & $\begin{array}{l}\text { Mean effect size } \\
\mathbf{( 9 5 \% ~ C l )}\end{array}$ & $\mathbf{Z}(\mathbf{p})$ \\
\hline $\begin{array}{l}6 \text { minute walking } \\
\text { test distance (m) }\end{array}$ & 5 & 101 & $72.17[45.71,98.62]$ & $5,35(<0,0001)$ \\
$\begin{array}{l}\text { Peak oxygen uptake } \\
\text { (mL/kg/min) }\end{array}$ & 3 & 73 & $2.14[0.40,3.88]$ & $2,41(0,02)$ \\
$\begin{array}{l}\text { Peak heart rate } \\
\text { (beats/min) }\end{array}$ & 3 & 75 & $2.11[-4.59,8.81]$ & $0,62(0,54)$ \\
\begin{tabular}{l} 
WHO-FC \\
\hline
\end{tabular} & 4 & 78 & $-0.24[-0.44,-0.04]$ & $1,57(0,12)$ \\
\hline
\end{tabular}

$n=$ number; $W H O-F C=$ World Health Organization Functional Class; $s P A P=$ peak systolic pulmonary artery pressure. 


\begin{tabular}{|c|c|c|c|c|c|c|c|c|c|c|c|}
\hline \multirow[b]{2}{*}{ Study or Subgroup } & \multicolumn{3}{|c|}{ Exercise } & \multicolumn{3}{|c|}{ Control } & \multicolumn{3}{|c|}{ Mean Difference } & \multirow{2}{*}{\multicolumn{2}{|c|}{$\begin{array}{c}\text { Mean Difference } \\
\text { IV, Random, } 95 \% \mathrm{Cl}\end{array}$}} \\
\hline & Mean & SD & Total & Mean & SD & Total & Weight & IV, Random, $95 \% \mathrm{Cl}$ & Year & & \\
\hline Mereles 2006 & 96 & 61 & 15 & -15 & 54 & 15 & $25.8 \%$ & $111.00[69.77,152.23]$ & 2006 & & $\longrightarrow$ \\
\hline Martinez-Quintana 2010 & -17 & 46.8 & 4 & -3 & 204 & 4 & $1.6 \%$ & $-14.00[-219.11,191.11]$ & 2010 & & \\
\hline Fox 2011 & 32 & 36.5 & 9 & -26 & 19.9 & 11 & $40.6 \%$ & $58.00[31.41,84.59]$ & 2011 & & - \\
\hline Ley 2013 & 91.4 & 66.2 & 10 & 16.9 & 39.8 & 10 & $21.2 \%$ & $74.50[26.63,122.37]$ & 2013 & & $\longrightarrow$ \\
\hline Chan 2013 & 56 & 80.3 & 10 & 12 & 102 & 13 & $10.7 \%$ & $44.00[-30.51,118.51]$ & 2013 & & \\
\hline Total $(95 \% \mathrm{Cl})$ & & & 48 & & & 53 & $100.0 \%$ & $72.51[45.97,99.06]$ & & & \\
\hline $\begin{array}{l}\text { Heterogeneity: } T_{a}{ }^{2}=26 \\
\text { Test for overall effect: } Z=\end{array}$ & $\begin{array}{l}.88 ; \mathrm{Chi}^{2} \\
5.35(\mathrm{P}<\end{array}$ & $\begin{array}{l}=5.72 \\
0.000\end{array}$ & $\begin{array}{l}\text { 2, df }= \\
\text { o1) }\end{array}$ & $4(P=0.2$ & $22) ; 1^{2}=$ & $=30 \%$ & & & & $\begin{array}{ccc}-200 & -100 & 0 \\
\text { favours control }\end{array}$ & $\begin{array}{rr}100 & 200 \\
\text { favours exercise }\end{array}$ \\
\hline
\end{tabular}

in patients with PAH [30]. Only three of the included studies reported exercise training related changes in oxygen uptake. Nevertheless, this was already sufficient to document a small but significant increase in peak $\mathrm{VO}_{2}$ following exercise training. This result is also in line with several other small-scale non-controlled studies [31] and adds further evidence to support the use of exercise training to increase peak $\mathrm{VO}_{2}$ in this patient population. Whereas the clinical significance of these small improvements $\left(+2.6 \mathrm{ml} / \mathrm{min} / \mathrm{kg}\right.$ peak $\left.\mathrm{VO}_{2}\right)$ in this population remains inconclusive, Groeppenhof et al. showed that among patients with $\mathrm{PAH}$, survivors have larger increases in exercise capacity compared to non-survivors [32].

The underlying mechanisms causing these training effects might be of both central pulmonary and cardiovascular as well as peripheral origin, but need to be further clarified. In addition, whether baseline and especially training-related changes in objective exercise capacity reflect a better prognosis both in short and longer term of patients with PAH still needs to be determined [30].

Exercise capacity is closely related to the ability to perform normal daily life activities. In turn, this closely relates to quality of life. Exercise tests can indirectly quantify shortness of breath and fatigue, two of the most common symptoms of PAH. Therefore, the change in 6MWD and peak $\mathrm{VO}_{2}$ from baseline to the end of an exercise training program might suggest symptomatic improvement over that time-period [33]. Although we could only show a tendency $(\mathrm{p}=0.12)$ toward a functional improvement by means of the WHO-FC scale, this was only based on four studies and more studies are warranted. Moreover, the effect of exercise training on quality of life in these patients needs further research due to the importance for both clinicians and patients.

\section{Limitations}

There are several limitations to our work. Although meta-analyses are no substitute for large well-designed controlled trials, the meta-analytical technique is probably the best method to systematically review previous work. Advantages are the greater precision of the estimates and the enhanced statistical power. In order to provide the most accurate summary of the effects of exercise training for PAH, the PRISMA statement was carefully followed [34]. A potential disadvantage of a meta-analysis is the heterogeneity of studies for instance due to variations in the exercise programs and the differences between patient populations [35]. Although random-effects models which incorporate heterogeneity into their model were used, some caution might be warranted with the interpretation given also the small number of studies and the small sample sizes. Further, as there were only 3 randomized trials, we also included 2 non-randomized studies. The results of those may be affected by confounding bias due to the absence of random assignment.

\section{Conclusions}

The findings from this systematic review and metaanalysis suggest that an exercise training program positively influences exercise tolerance and functional capacity in patients with PAH. Physicians need to become aware of

\begin{tabular}{|c|c|c|c|c|c|c|c|c|c|c|c|}
\hline Study or Subgroup & \multicolumn{3}{|c|}{ Exercise } & \multicolumn{3}{|c|}{ Control } & Weight & \multicolumn{2}{|l|}{ Mean Difference } & \multicolumn{2}{|c|}{$\begin{array}{c}\text { Mean Difference } \\
\text { IV, Random, 95\% Cl }\end{array}$} \\
\hline Mereles 2006 & 2.2 & 3.44 & 15 & -0.5 & 3.21 & 15 & $55.3 \%$ & $2.70[0.32 .5 .08]$ & 2006 & & - \\
\hline Fox 2011 & 1.1 & 3.32 & 11 & -0.5 & 3.32 & 9 & $36.7 \%$ & $1.60[-1.32,4.52]$ & 2011 & - & - \\
\hline Chan 2013 & 1.4 & 8.94 & 10 & 0.4 & 5.42 & 13 & $8.0 \%$ & $1.00[-5.28,7.28]$ & 2013 & & \\
\hline Total $(95 \% \mathrm{Cl})$ & & & 36 & & & 37 & $100.0 \%$ & $2.16[0.39,3.93]$ & & & \\
\hline $\begin{array}{l}\text { Heterogeneity: Tauz } \\
\text { Test for overall effect }\end{array}$ & $\begin{array}{l}0.00 ; C \\
Z=2.39\end{array}$ & $\begin{array}{l}h^{2}=0 \\
(P=0\end{array}$ & $\begin{array}{l}47, d f= \\
0.02)\end{array}$ & $=2(\mathrm{P}=$ & $0.79) ;$ & $F^{2}=0 \%$ & & & & $\begin{array}{cc}1 & 1 \\
-4 & -2 \\
\text { favours control }\end{array}$ & \begin{tabular}{|ccc} 
& 1 & 1 \\
0 & 2 & 4 \\
1 & favours exercise
\end{tabular} \\
\hline
\end{tabular}


the positive effects of this non-pharmacological intervention that can improve the integrated care of patients with PAH. Given the small number of available studies and the small sample sizes, we believe that this topic deserves a more in-depth investigation. Well-designed randomized clinical trials investigating the effects of exercise training on exercise capacity and patient outcomes are needed to confirm our results.

\section{Additional files}

Additional file 1: Funnel plots for 6 minute walking distance. Additional file 2: Funnel plots for peak oxygen uptake.

\section{Abbreviations}

PAH: Pulmonary arterial hypertension; $\mathrm{Cl}$ : Confidence intervals; MeSH: Medical subject heading; 6MWD: 6 minute walking distance; peak $\mathrm{VO}_{2}$ : Peak oxygen uptake; WHO-FC: World Health Organization Functional Class; SD: Standard deviation.

\section{Competing interests}

The authors declare that they have no competing interests.

\section{Authors' contributions}

All authors significantly contributed to the study and take responsibility for the integrity of the work as a whole, from inception to published article. RB conceived of the study, participated in its design and coordination, extracted and statistically analyzed the data and drafted the first version of the manuscript. AA extracted the data and revised the manuscript it critically for important intellectual content. VC participated in the study design performed and controlled the statistical analyses on the data; she provided consensus when data extracted by RB and AA was inconsistent and revised the manuscript it critically for important intellectual content. All authors read and approved the final manuscript.

\section{Acknowledgements}

RB has been awarded research grants from the research foundation Flanders (FWO) and from the Belgian Fund for Cardiac Surgery. VAC is supported as a postdoctoral research fellow by research foundation Flanders (FWO).

\section{Received: 6 January 2015 Accepted: 31 March 2015}

\section{Published online: 22 April 2015}

\section{References}

1. Galie N, Hoeper MM, Humbert M, Torbicky A, Vachiery JL, Barbera JA, et al. Guidelines for the diagnosis and treatment of pulmonary hypertension: the Task Force for the Diagnosis and Treatment of Pulmonary Hypertension of the European Society of Cardiology (ESC) and the European Respiratory Society (ERS), endorsed by the International Society of Heart and Lung Transplantation (ISHLT). Eur Heart J. 2009;30:2493-537.

2. Desai SA, Channick RN. Exercise in patients with pulmonary arterial hypertension. J Cardiopulm Rehabil Prev. 2008;28:12-6.

3. Arena R, Lavie CJ, Milani RV, Myers J, Guazzi M. Cardiopulmonary exercise testing in patients with pulmonary arterial hypertension: an evidence-based review. J Heart Lung Transplant. 2010;29:159-73.

4. Taylor RS, Sagar VA, Davies EJ, Briscoe S, Coats AJ, Ebrahim S, et al. Exercisebased rehabilitation for heart failure. Cochrane Database Syst Rev. 2014:4:CD003331.

5. Langer D, Hendriks E, Burtin C, Probst V, Van Der Schans C, Paterson W, et al. A clinical practice guideline for physiotherapists treating patients with chronic obstructive pulmonary disease based on a systematic review of available evidence. Clin Rehabil. 2009;23:445-62.

6. Vanhees L, Rauch B, Piepoli M, Van Buuren F, Takken T, Börjesson M, et al. Importance of characteristics and modalities of physical activity and exercise in the management of cardiovascular health in individuals with cardiovascular disease (Part III). Eur J Prev Cardiol. 2012;19:1333-56.
7. Duppen N, Takken T, Hopman MT, Ten Harkel AD, Dulfer K, Utens EM, et al. Systematic review of the effects of physical exercise training programmes in children and young adults with congenital heart disease. Int J Cardiol. 2013;168:3.

8. Physiotherapy evidence database (PEDro).[http://www.pedro.org.au]

9. de Morton NA. The PEDro scale is a valid measure of the methodological quality of clinical trials: a demographic study. Aust J Physiother. 2009;55:129-33.

10. Maher CG, Sherrington C, Herbert RD, Moseley AM, Elkins M. Reliability of the PEDro scale for rating quality of randomized controlled trials. Phys Ther. 2003;83:713-21.

11. Follmann D, Elliott $P$, Suh I, Cutler J. Variance imputation for overviews of clinical trials with continuous response. J Clin Epidemiol. 1992;45:769-73.

12. Dersimonian R, Kacker R. Random-effects model for meta-analysis of clinical trials: an update. Contemp Clin Trials. 2007;28:105-14.

13. Schmidt FL, Oh IS, Hayes TL. Fixed- versus random-effects models in metaanalysis: model properties and an empirical comparison of differences in results. Br J Math Stat Psychol. 2009;62:97-128.

14. Borenstein MHL, Higgins JPT, Rothstein HR. Introduction to meta-analysis. New York: John Wiley \& Sons, Ltd; 2009. p. 272-92.

15. Chan L, Chin LM, Kennedy M, Woolstenhulme JG, Nathan SD, Weinstein AA, et al. Benefits of intensive treadmill exercise training on cardiorespiratory function and quality of life in patients with pulmonary hypertension. Chest. 2013;143:333-43.

16. Weinstein AA, Chin LM, Keyser RE, Kennedy M, Nathan SD, Woolstenhulme $\mathrm{JG}$, et al. Effect of aerobic exercise training on fatigue and physical activity in patients with pulmonary arterial hypertension. Respir Med. 2013;107:778-84.

17. Martinez-Quintana E, Miranda-Calderin G, Ugarte-Lopetegui A, RodriguezGonzalez F. Rehabilitation program in adult congenital heart disease patients with pulmonary hypertension. Congenit Heart Dis. 2010;5:44-50.

18. Mereles D, Ehlken N, Kreuscher S, Ghofrani S, Hoeper MM, Halank M, et al. Exercise and respiratory training improve exercise capacity and quality of life in patients with severe chronic pulmonary hypertension. Circulation. 2006;114:1482-9.

19. Fox BD, Kassirer M, Weiss I, Raviv Y, Peled N, Shitrit D, et al. Ambulatory rehabilitation improves exercise capacity in patients with pulmonary hypertension. J Card Fail. 2011;17:196-200.

20. Ley S, Fink C, Risse F, Ehlken N, Fischer C, Ley Zaporozhan J, et al. Magnetic resonance imaging to assess the effect of exercise training on pulmonary perfusion and blood flow in patients with pulmonary hypertension. Eur Radiol. 2013;23:324-31.

21. ATS statement. Guidelines for the six-minute walk test. Am J Respir Crit Care Med. 2002;166:111-7.

22. Lacasse Y, Brosseau L, Milne S, Martin S, Wong E, Guyatt GH, et al. Pulmonary rehabilitation for chronic obstructive pulmonary disease. Cochrane Database Syst Rev. 2002;3:CD003793.

23. Peytremann-Bridevaux I, Staeger P, Bridevaux PO, Ghali WA, Burnand B. Effectiveness of chronic obstructive pulmonary disease-management programs: systematic review and meta-analysis. Am J Med. 2008;121:433-43.

24. Van der Meer $S$, Zwerink $M$, van Brussel $M$, van der Valk $P$, Wajon $E$, van der Palen J. Effect of outpatient exercise training programmes in patients with chronic heart failure: a systematic review. Eur J Prev Cardiol. 2012;19(4):795-803.

25. Rasekaba T, Lee AL, Naughton MT, Williams TJ, Holland AE. The six-minute walk test: a useful metric for the cardiopulmonary patient. Intern Med J. 2009:39:495-501

26. Savarese G, Paolillo S, Costanzo P,D, Amore C, Cecere M, Losco T, et al. Do changes of 6-minute walk distance predict clinical events in patients with pulmonary arterial hypertension? A meta-analysis of 22 randomized trials. J Am Coll Cardiol. 2012;60:1192-201.

27. Macchia A, Marchioli R, Marfisi R, Scarano M, Levantesi G, Tavazzi L, et al. A meta-analysis of trials of pulmonary hypertension: a clinical condition looking for drugs and research methodology. Am Heart J. 2007;153:1037-47.

28. Golpe R, Castro-Anon O, Perez-de-Llano LA, Gonzalez Juanatey C, Muniz Fernandez C, Testa Fernandez A, et al. Prognostic significance of six-minute walk test in non-group 1 pulmonary hypertension. Heart Lung. 2014;43:72-6.

29. Hansen JE, Sun XG, Yasunobu Y, Garafano RP, Gates G, Barst RJ, et al. Reproducibility of cardiopulmonary exercise measurements in patients with pulmonary arterial hypertension. Chest. 2004;126:816-24. 
30. Paolillo S, Farina S, Bussotti M, lorio A, PerroneFilardi P, Piepolil MF, et al. Exercise testing in the clinical management of patients affected by pulmonary arterial hypertension. Eur J Prev Cardiol. 2012;19:960-71.

31. Zafrir B. Exercise training and rehabilitation in pulmonary arterial hypertension: rationale and current data evaluation. J Cardiopulm Rehabil Prev. 2013;33:263-73.

32. Groepenhoff H, Vonk-Noordegraaf A, van de Veerdonk MC, Boonstra A, Westerhof N, Bogaard HJ. Prognostic relevance of changes in exercise test variables in pulmonary arterial hypertension. PLoS One. 2013;8:e72013.

33. Chua R, Keogh AM, Byth K, O'Loughlin A. Comparison and validation of three measures of quality of life in patients with pulmonary hypertension. Intern Med J. 2006;36:705-10.

34. Liberati A, Altman DG, Tetzlaff J, Mulrow C, Gøtzsche PC, loannidis JP, et al. The PRISMA Statement for Reporting Systematic Reviews and Meta-Analyses of Studies That Evaluate Health Care Interventions: Explanation and Elaboration. BMJ. 2009;339:b2700.

35. Fagard RH, Staessen JA, Thijs L. Advantages and disadvantages of the metaanalysis approach. J Hypertens Suppl. 1996;14:S9-12.

\section{Submit your next manuscript to BioMed Central and take full advantage of:}

- Convenient online submission

- Thorough peer review

- No space constraints or color figure charges

- Immediate publication on acceptance

- Inclusion in PubMed, CAS, Scopus and Google Scholar

- Research which is freely available for redistribution 